\title{
Analysis of Non-polar Chemical Profile of Melia Azedarach L.
}

Habib, R. ${ }^{1}$, Mohyuddin, $\mathbf{A}^{1}$., Khan, $Z^{2}$. and Mahmood, $\mathbf{T}^{\mathbf{3}}$.

${ }^{1}$ Department of Chemistry, University of Management and Technology, Lahore

2 Department of Botany, GC University, Lahore

${ }^{3}$ Central Research Lab, Lahore College for Women University, Lahore

*rabiraho@gmail.com,

\begin{abstract}
Medicinal plants are conventionally used for the treatment of various diseases due to their world-wide occurrence and least side effects. Melia azedarach L. belongs to the family Meliaceae, is a highly significant medicinal plant. Extracts of $M$. azedarach obtained from its different parts such as seed, fruit, flower, leaf, and young branches are reported to exhibit antifungal, antihelmintic, nematicidal, diuretic, cytotoxic, antiproliferative, insecticidal and antioxidant activities. Thus the aim of this study was to explore the chemical profile of non-polar extract of $M$. azedarach leaves through GC-MS analysis. The identification of phytochemical compounds is based on molecular ion peak, base peak, and fragmentation pattern. GC-MS analysis of hexane extract of M. azedarach showed a highly complex profile, containing ketones, ethers, fatty acid derivatives, methyl esters, 1,3-dipalmitate, 7,8-dihydrocarpesterol, and 2Undecanol. This study will be useful to explore the active components of medicinal plants and can validate their medicinal value.
\end{abstract}

Keywords: Melia azedarach L., Meliaceae, GC-MS method, Phytochemical compound.

\section{Introduction}

There is an increasing demand for the herbal medicine to cure variety of diseases as these medicines are efficient and safe without any side effects as compared to synthetic drugs [1]. For this purpose, scientist, botanists, chemists, and pharmacists all over the world are working on herbal medicines [2]. Melia azedarach Linn. (M. azedarach) commonly known as chinaberry or Persian lilac tree is a plant species of the family Meliaceae that contain 45 genus and 750 species. It is deciduous tree of medium sized that grows to a height of five to fifteen meter tall and thirty to sixty $\mathrm{cm}$ in diameter. It can be grown successfully in a wide variety of situations even in alkaline soil where other trees might fail to grow. It is native to Indochina, Pakistan, India, Australia, and Southeast Asia. It is cultivated in most of the countries located in tropics and subtropical region. This plant has long been known as an insecticidal and medicinal plant all over the world due to its world-wide availability and fewer side effects. Extracts of $M$. 
azedarach obtained from its different parts such as seed, fruit, flower, leaf, and young branches have been used for the treatment of diabetes, malaria, intestinal worms, cough, nausea, vomiting and paroxysmal fever, and skin disease [3-5].

GC-MS has been known as a powerful technique for providing metabolic profiling of plants [6-9]. Hexane extracts of many species of Meliaceae family are analyzed by this technique but there has been no report on GC-MS of hexane extract of M. azedarach or any species of genus Melia. Non polar profile of $M$. azedarach has not been explored yet. Therefore, the aim of the study was to explore the chemical profile of non-polar extract of $M$. azedarach leaves through GC-MS analysis.

\section{Material and Methods}

2.1. Preparation of plant extract: The fresh leaves of plant $M$. azedarach was collected from the Botanical Garden of Government College University, Lahore and washed individually to remove impurities and dried under shade. Dried leaves were crushed into fine powder using a grinder.

The dried plant powder were weighed and dipped in a hexane and left for seven days. The hexane extract was then filtered. The hexane extract was concentrated under reduced pressure and low temperature in a Rotary Evaporator. The semi solid extract were obtained.

2.2. Phytochemical analysis of plant extract: Phytochemical analysis were carried out by employing standard procedures to sort out the presence of flavonoids, alkaloids, tannins, saponins and steroids in hexane extract of Melia azedarach $[10,11]$.

2.3. Preparation of sample for GC/MS analysis: A measured amount of semi solid was re-dissolved in $n$-hexane of GC grade and micro-filtered to prepare the samples of $5.0 \mathrm{mg} / 10 \mathrm{~mL}$.

2.4. Gas Chromatography Mass Spectrometry analysis: A GC-MS analysis was carried out on a Shimadzu GCMS-QP2010A system in EI mode $(70 \mathrm{eV})$ with DB-5MS capillary column $(30 \mathrm{~m} \times 0.25 \mathrm{~mm}$ i.d., film thickness: $0.25 \mu \mathrm{m}$, J and W scientific, Fulsom, CA, USA. $1 \mu \mathrm{L}$ of samples were injected at $250{ }^{\circ} \mathrm{C}$ with a split ratio of 50/50 under electronic pressure to maintain a constant flow $(0.67$ $\mathrm{mL} / \mathrm{min}$ ) of the helium carrier gas. The oven temperature was programmed from $150{ }^{\circ} \mathrm{C}$ for $4 \mathrm{~min}$ and heated to $300{ }^{\circ} \mathrm{C}$ at a rate of $3{ }^{\circ} \mathrm{C} / \mathrm{min}$ and kept constant at this temperature for $2 \mathrm{~min}$. The mass spectrometer was set to scan the mass range 40-600 amu with ion source temperature $200{ }^{\circ} \mathrm{C}$ and interface temperature was $250{ }^{\circ} \mathrm{C}$. Analyses were performed in triplicate with a blank run after every analysis. The resulting data was interpreted by using Shimadzu Lab Solution, GCMS Postrun analysis software. Compounds were identified by comparing the ions

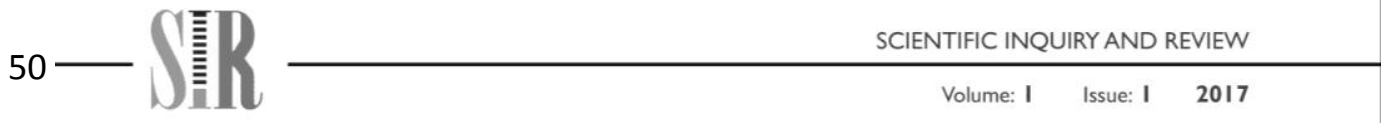


fragmentation pattern of mass spectra with those of known compounds stored in NIST 147 and NIST 127 libraries.

\section{Results and Discussion}

The genus Melia is famous for the presence of liminoids and terpenoids that are water-insoluble plant components [12]. Previous researches have proved that these compounds have diverse effect against pathogens. Moreover, non polar profile of $M$. azedarach has not been explored yet. The waxy coating of leaves can only be dissolved by non polar solvent because waxes are non polar in nature. Therefore, the leaves of $M$. azedarach were extracted with n-hexane in order to isolate the wax.

3.1. Phytochemical analysis of plant extract: The phytochemical analysis was carried out and it was seen that alkaloids and flavonoids are absent in hexane extract of $M$. azedarach, whereas it contain tannins, terpenes, quinines, saponins and steroids as given in Table1.

Table1.

Phytochemical Analysis

\begin{tabular}{|c|c|c|}
\hline Experiment & Observation & Inference \\
\hline \multicolumn{3}{|l|}{ Test for Alkaloids } \\
\hline Mayer's test & No yellow ppt. & Alkaloids absent \\
\hline Wagner's test & No reddish brown ppt. & Alkaloids absent \\
\hline \multirow[t]{2}{*}{ Dragendorff test } & & Alkaloids absent \\
\hline & \multicolumn{2}{|c|}{ Test for Tannins } \\
\hline $5 \mathrm{ml}$ extract +6 drops $\mathrm{FeCl}_{3}$ & & Tannins present \\
\hline $\begin{array}{l}\text { Test for Coumarins } \\
\text { plant extract }+1 \mathrm{~N} \mathrm{NaOH}+\end{array}$ & Yellow floresence & \\
\hline Pass through Uvlight & & Coumarins present \\
\hline Test for Flavonoids & yellow florescence is not produced & \\
\hline \multicolumn{3}{|l|}{ Plant extract $+2 \mathrm{ml} \mathrm{AlCl}_{3}$} \\
\hline \multirow{2}{*}{\multicolumn{3}{|c|}{ Test for Saponins }} \\
\hline & & \\
\hline $\begin{array}{l}\text { vigorously } \\
\text { Test for Steroids }\end{array}$ & Violet color & Saponins present \\
\hline Leibermann-Burchard test & Red color & \\
\hline Test for Anthraquinon & & Steroids present \\
\hline $\begin{array}{c}\text { Plant extract }+ \text { few drops N,N- } \\
\text { dimethylanaline }\end{array}$ & & $\begin{array}{l}\text { Anthraquinonses } \\
\text { present }\end{array}$ \\
\hline
\end{tabular}

3.2. Gas Chromatography Mass Spectrometry analysis: Gas Chromatography and Mass spectroscopy analysis of compounds was carried out in n-hexane leaf extract of $M$. azedarach (Figure1). 


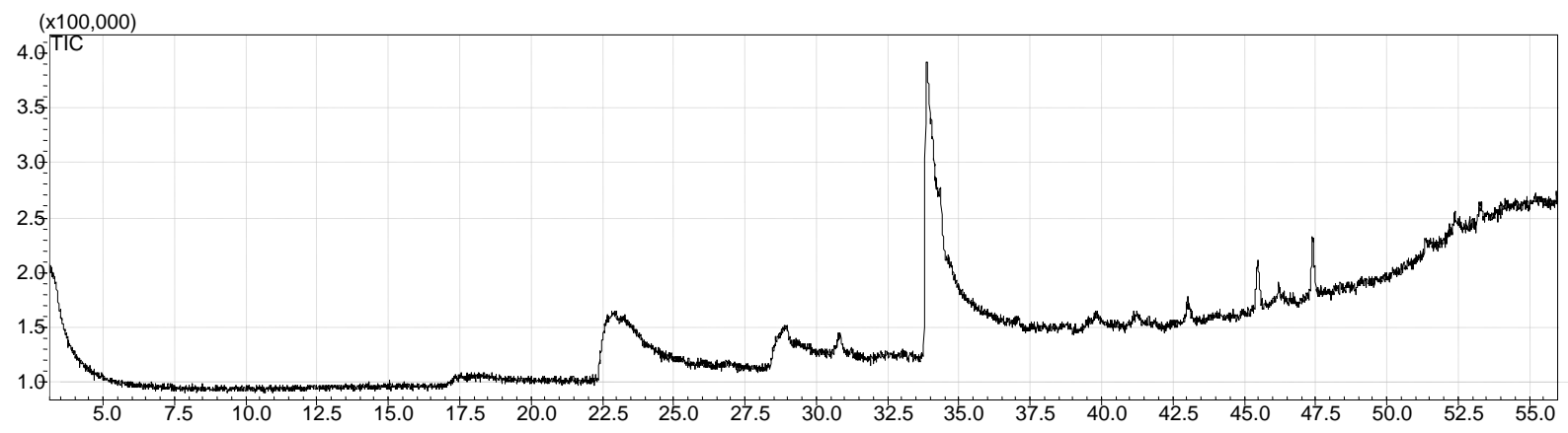

Figure 1. GC chromatogram of $n$ - hexane extract of $M$. azedarach leaves

Different compounds were identified in the hexane extract of $M$. azedarach on the basis of retention time, molecular ion peak, base peak, and mass fragmentation pattern. Eight peaks from non-polar plant extract were identified as: 2-Undecanol, Methyl 4, 6-decadienyl ether, 13-Docosenoic acid, 7, 8Dihydrocarpesterol, Glutaric acid, dimethyl ester, Nonanoic acid, 1, 2, 3propanetriyl ester, Glycerol 2-acetate 1, 3-dipalmitate and Docosenoic acid, 1 methyl-butyl ester as shown in Table2.

Table2.

Compounds from hexane extract of $M$. azedarach

\begin{tabular}{|l|c|c|}
\hline \multicolumn{1}{|c|}{ Name of compound } & Retention Time (mins) & Base Peak (m/z) \\
\hline 2-Undecanol & 22.39 & 45 \\
Methyl 4, 6-decadienyl ether & 22.45 & 45 \\
13-Docosenoic acid & 33.88 & 55 \\
7, 8-Dihydrocarpesterol & 45.48 & 414 \\
Glutaric acid, dimethyl ester & 47.24 & 133 \\
Nonanoic acid, 1, 2, 3-propanetriyl ester & 52.09 & 151 \\
Glycerol 2-acetate 1, 3-dipalmitate & 52.18 & 40 \\
Docosenoic acid, 1 methyl-butyl ester & 54.90 & 44 \\
\hline
\end{tabular}

2-Undecanol was eluted at $22.39 \mathrm{~min}$. Base peak of the compound was observed at $\mathrm{m} / \mathrm{z} 45$. The fragment ions observed $\mathrm{m} / \mathrm{z} 40,60,83,97,150$. The fragment ion observed at $\mathrm{m} / \mathrm{z} 83$ was due to the loss of $-\mathrm{CH} 2$ group from molecular ion (M+). Methyl 4, 6-decadienyl ether was eluted at $22.45 \mathrm{~min}$. Base peak of the compound was observed at $\mathrm{m} / \mathrm{z} 45$. The fragment ions observed $\mathrm{m} / \mathrm{z}$ $41,56,70,84,150$. The fragment ion observed at $\mathrm{m} / \mathrm{z} 70$ was due to the loss of $\mathrm{CH} 2$ group from $\mathrm{M}+$. 13-Docosenoic acid was eluted at $33.88 \mathrm{~min}$. Base peak of the compound was observed at $\mathrm{m} / \mathrm{z} 55$. The fragment ions observed $\mathrm{m} / \mathrm{z} 69,83$, $97,185,207,320$. The fragment ion observed at $\mathrm{m} / \mathrm{z} 83$ was due to the loss of $\mathrm{CH} 2$ group from $\mathrm{M}+.7,8$-Dihydrocarpesterol was eluted at $45.48 \mathrm{~min}$. Base peak of the compound was observed at $\mathrm{m} / \mathrm{z} 441$. The fragment ions observed at $\mathrm{m} / \mathrm{z} 91$,

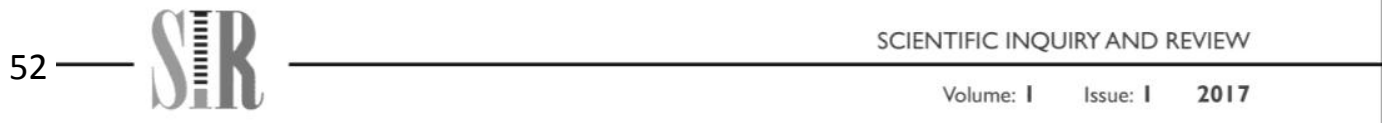


$133,147,191,208,335,441$. The fragment ion observed at $\mathrm{m} / \mathrm{z} 191$ was due to the loss of -OH group from $\mathrm{M}+$. Glutaric acid, dimenthyl ester was eluted at 47.24 $\mathrm{min}$. Base peak of the compound was observed at $\mathrm{m} / \mathrm{z} 133$. The fragment ions observed $\mathrm{m} / \mathrm{z}$ 40, 69, 83, 193, 209, 281.The fragment ion observed at $\mathrm{m} / \mathrm{z} 40$ was due to the loss of -C2H5 group from $\mathrm{M}+$. Nonanoic acid, 1, 2, 3-propanetriyl ester was eluted at $52.09 \mathrm{~min}$. Base peak of the compound was observed at $\mathrm{m} / \mathrm{z} 151$. The fragment ions observed $\mathrm{m} / \mathrm{z} \mathrm{44}, 68,85,100,169,207,281,335$. The fragment ion observed at $\mathrm{m} / \mathrm{z} 68$ was due to the loss of $-\mathrm{OH}$ group from $\mathrm{M}+$. Glycerol 2-acetate 1, 3-dipalmitate was eluted at $52.18 \mathrm{~min}$. Base peak of the compound was observed at $\mathrm{m} / \mathrm{z} 40$. The fragment ions observed $\mathrm{m} / \mathrm{z} 68,100,169$, 209, 267, 335, 441. Docosenoic acid, 1 methyl-butyl ester was eluted at 54.90 min. Base peak of the compound was observed at $\mathrm{m} / \mathrm{z} 44$. The fragment ions observed $\mathrm{m} / \mathrm{z} 77,101,137,150,208,341$. The fragment ion observed at $\mathrm{m} / \mathrm{z} 177$ was due to the loss of $-\mathrm{CH} 3$ group from $\mathrm{M}+$.

\section{Conclusion}

Traditionally, medicinal plants are largely used to cure many diseases owing to their least side effects. M. azedarach L. belongs to potent medicinal plant family Meliaceae. This was the first report on GC-MS of Hexane extract of M. azedarach. The results showed that non polar extract of the plant contained a variety of compounds such as ketones, ethers, fatty acid derivatives, methyl esters, 1,3-dipalmitate, 7,8-dihydrocarpesterol, and 2-Undecanol. This will contribute in completing the chemical profile of M. azedarach. 


\section{References}

[1] Hariprasad PS, Ramakrishnan N. GC-MS analysis of Rumex vesicarius L. Int J Drug Dev Res. 2011;3(2):256-263.

[2] Walli TE. Text book of pharmacognosy. $2^{\text {nd }}$ Ed. London: J and A Churchill; 1951.

[3] Azam MM, Mamun-Or-Rashid AN, Towfique NM, Sen MK, Nasrin S. Pharmacological potentials of Melia azedarach L. A review. Am $J$ BioSci.2013;1(2):44-49.

[4] Sultana S, Akhtar N, Asif HA. Phytochemical screening and antipyretic effects of hydro-methanol extract of Melia azedarach leaves in rabbits. Bangladesh J Pharmacol. 2013;8(2):214-217.

[5] Nadkarni KM. Indian Materia Medica. Bombay: Popular Prakashan;1954. 784-785 p.

[6] Fernie AR, Trethewey RN, Krotzky AJ, Willmitzer L. Metabolite profiling: from diagnostics to systems biology. Nat Rev Mol Cell Biol. 2004;5(9):763769.

[7] Sumner LW, Mendes P, Dixon RA. Plant metabolomics: largescale phytochemistry in the functional genomics era. Phytochemistry. 2003;62(6):817-836.

[8] Fiehn O. Metabolomics - the link between genotypes and phenotypes. Plant Mol Biol. 2002;48(1-2):155-171.

[9] Kell DB, Brown M, Davey HM, Dunn WB, Spasic I, Oliver SG. Metabolic footprinting and systems biology. Nat Rev Microbiol. 2005;3(7):557-565.

[10] Emeruwa AC. Antimicrobial substances from Carica papaya fruit extracts. Journal of Natural Products. 1982;45(2):123-127.

[11] Evans WC. Trease and Evans Pharmacognosy. $5^{\text {th }}$ Ed. Edinburgh: Saunders Elsevier; 2002.

[12] Satyavati GV, Raina MK, Sharma M, Editors. Medicinal Plants of India. New Delhi: Indian council of medical research; 1976. 201-206 p.

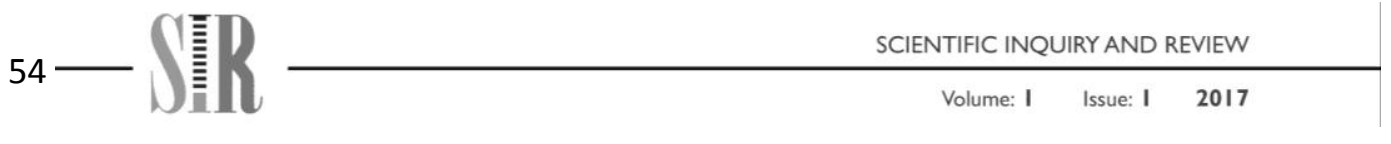

